\title{
FTO rs9939609 Does Not Interact with Physical Exercise but Influences Basal Insulin Metabolism in Brazilian Overweight and Obese Adolescents
}

\author{
Gabrielle Araujo do Nascimento $\left(\mathbb{D},{ }^{1}\right.$ Neiva Leite, ${ }^{2}$ Lupe Furtado-Alle, ${ }^{1}$ \\ Mayza Dalcin Teixeira, ${ }^{1}$ Ricardo Lehtonen Rodrigues de Souza, ${ }^{1}$ Gerusa Eisfeld Milano $\left(\mathbb{D},{ }^{2}\right.$ \\ Larissa Rosa da Silva, ${ }^{2}$ Juliana Pizzi, ${ }^{2}$ Wendell Arthur Lopes $\mathbb{D}^{3}{ }^{3}$ \\ Maria de Fátima Aguiar Lopes, ${ }^{2}$ Ana Cláudia Kapp Titski, ${ }^{2}$ and Luciane Viater Tureck $\mathbb{D}^{1,4}$ \\ ${ }^{1}$ Department of Genetics, Centro Politécnico, Setor de Ciências Biológicas, Federal University of Paraná, Francisco H. dos Santos, \\ 210 Jardim das Américas, 81531-970 Curitiba, PR, Brazil \\ ${ }^{2}$ Department of Physical Education, Federal University of Paraná, Coração de Maria, 92 Jardim Botânico, 80215-370 Curitiba, \\ PR, Brazil \\ ${ }^{3}$ Department of Physical Education, State University of Maringa, Av. Colombo 5790, 87020-900 Maringa, PR, Brazil \\ ${ }^{4}$ Academic Department of Education, Federal University of Technology-Paraná, Av. Monteiro Lobato Km 04, \\ 84016-210 Ponta Grossa, PR, Brazil \\ Correspondence should be addressed to Luciane Viater Tureck; luviater@gmail.com
}

Received 30 November 2017; Revised 23 March 2018; Accepted 8 April 2018; Published 26 April 2018

Academic Editor: Moonseong Heo

Copyright (c) 2018 Gabrielle Araujo do Nascimento et al. This is an open access article distributed under the Creative Commons Attribution License, which permits unrestricted use, distribution, and reproduction in any medium, provided the original work is properly cited.

\begin{abstract}
Purpose. The rs9939609 SNP (T>A) in FTO gene is associated with obesity and type 2 diabetes. The present study aimed at verifying whether this SNP influenced biochemical outcomes of children and adolescents who are overweight/obese submitted to a program of physical exercise and also if there was influence on basal levels of these biochemical variables. Methods. The sample was composed by 432 children and adolescents grouped in three ways (obese, overweight, and normal weight); of these, 135 children and adoloescents who are obese and overweight were submitted to a physical exercise program for 12 weeks. All were genotyped by TaqMan SNP genotyping assay. Results. The children and adolescents who are overweight/obese and carriers of AA genotype had higher levels of insulin $(p=0.03)$ and HOMA $(p=0.007)$ and lower levels of glucose $(p=0.003)$, but the SNP did not modulate the response to physical exercise. Conclusions. In our study, the rs9939609 AA genotype was associated with parameters related to insulin metabolism but did not interact with physical exercise.
\end{abstract}

\section{Introduction}

Obesity is a multifactorial disease influenced by several genetic factors, including the fat mass and obesity-associated (FTO) gene [1,2], which is expressed in the whole organism, mainly in hypothalamus, and thus associated with energy balance regulation [3]. FTO gene product is a 2-oxoglutarate dependent nucleic acid demethylase [4] which can have several target genes, including genes related to metabolism.

One of its most studied SNPs is the rs9939609 SNP $(\mathrm{T}>\mathrm{A})$, associated with obesity, type 2 diabetes, and other metabolic complications $[1,5,6]$. The body weight increase associated with rs 9939609 A-allele could be related to an increase in FTO expression, since FTO transcripts are more abundant in risk allele carriers [7].

Many studies have shown association between A-allele and increased food intake and reduced satiety [8-11]; however, the interaction of the rs9939609 SNP with energy expenditure has not yet been clarified, since some studies found interaction and others did not [12].

Besides the effect induced by rs 9939609 A-allele in several basal metabolic parameters [13-16], it can also interfere in the 
response promoted by physical and/or dietary interventions. Some studies have found a reduction in levels of cholesterol, low-density lipoprotein cholesterol (LDL-C), insulin, and HOMA-IR in A-allele carries in response to diet $[17,18]$. Regarding the physical exercise, any study that analyzed the interaction of the rs9939609 A-allele on biochemical outcomes was not found.

Efforts have been adopted to understand the interactions between genetic and environmental factors underlying the complex pathologies. In this sense, the identification of modifiable factors that may contribute to decrease the genetic predisposition on metabolic disorders is important for prevention and treatment. Considering the potential influence of rs9939609 on biochemical variables that predict essential metabolic functions, and the lack of studies with FTO and physical exercise interaction, the present study investigated the rs9939609 SNP (T $>$ A) effect on biochemical outcomes induced by physical exercise in children and adolescents who are overweight/obese.

\section{Materials and Methods}

2.1. Subjects. The study was composed by 432 children and adolescents (290 boys and 142 girls), of which 169 had normal weight and 263 had overweight or were obese ( 80 overweight and 183 obese), according to parameters defined by WHO [19]. The mean overall age was $13.51 \pm 0.09$ years old (aged $8-17 \mathrm{y}$ ), and the mean BMI Z-score in the overweight/obese group was 2.69 before the exercise and 2.73 after the exercise. In the normal weight group, the mean BMI $Z$-score was -0.22 . This study was limited to analysis of the biochemical variables in these individuals. Some of them were analyzed in a previous study that was limited to anthropometric variables analysis [20].

The recruitment of children and adolescents was carried out in public schools of the state of Paraná, Southern Brazil, with the following inclusion criteria: children and adolescents who have medical liberation for physical exercise and do not use drugs that could interfere on weight control and/or lipid levels. An invitation to participate in the research was made to those individuals who met the criteria and those who accepted signed the free and informed consent term, along with the legal responsible consent [20]. The study was approved by the ethics committee of the Federal University of Paraná (UFPR) (protocol number 765.184/2003-11) [20].

Weight and height were measured with an accuracy of $0.1 \mathrm{~kg}$ and $0.1 \mathrm{~cm}$, respectively. BMI was calculated as weight in kilograms divided by the square of height in meters and then converted into BMI Z-score according to WHO [19]. The children and adolescents were considered overweight when their BMI $Z$-score was between +1 and +2 and obese when their BMI $Z$-score was more than +3 [19].

2.2. Biochemical Variables. The blood samples were collected, and total cholesterol (TC), HDL-C, and TG were measured by standard procedures in private partner laboratories and in the clinical analyzes laboratory of UFPR.
Blood glucose levels were determined by the enzymatic method, and insulin was measured by the chemiluminescence immunoassay technique by automated equipment. LDL-C levels were calculated using the Friedewald equation [21], homeostatic model assessment for insulin resistance (HOMA-IR) was calculated using the formula fasting blood glucose $(\mu \mathrm{U} / \mathrm{ml}) \times$ insulin ( $\mathrm{mMol} / \mathrm{l}) / 22.5$ [22], and the quantitative insulin sensitivity check index (QUICKI) was calculated using the formula $1 /(\log$ (fasting insulin) $(\mathrm{mU} / \mathrm{ml}) \times \log$ (fasting blood glucose) $(\mathrm{mMol} / \mathrm{l}))[23]$. These variables were measured before and after the exercise program.

2.3. Physical Exercise Intervention Program. Of the 263 children and adolescents who are overweight or obese and who participated in the study, 135 were submitted to an after-school exercise program. This research is part of a larger project the objective of which was to analyze the response of the children and adolescents who are overweight or obese to different physical exercises [24-27].

The exercise intervention programs were carried out in a special session offered in the school gym (land-based aerobic exercise, high-intensity interval training (HIIT), and combined training) or in the university setting (water walking).

Each student participated in one of the four different physical exercise programs: land-based aerobic exercise, HIIT, combined training, or water walking. Each physical exercise program consisted of 3 sessions per week for 12 weeks. They were instructed in the FITT principles (frequency, intensity, time, and type of exercise) by physical education teachers in the school or in the university setting. The minimal adherence accepted was $70 \%$ of attendance.

The details of exercise programs are described below and also in previously published works [20,24-27].

The land-based aerobic exercise $(n=53)$ was performed in a total of 110 minutes, divided into 45 minutes of walking, 45 minutes of indoor cycling, and 20 minutes of stretching. The reserve heart rate (RHR) was accessed, with 35\% to $55 \%$ in the first to fourth week, $45 \%$ to $65 \%$ in the fifth to eight week, and $55 \%$ to $75 \%$ in the last weeks [24].

HIIT $(n=27)$ was performed in 45 minutes in each session, and the students did warming-up exercises, running for 30 seconds at $100 \%$ speed peak effort, walking for 60 seconds at $50 \%$ peak velocity (active recovery period), and relaxing. The exercise was composed by two sets, and there were four minutes of rest between sets. The training progressed as the weeks passed: in the first week, the set was composed by $4 \times 30 \mathrm{~s} / 60 \mathrm{~s}$; in the week 2 , it was composed by $5 \times 30 \mathrm{~s} / 60 \mathrm{~s}$; in the week 3 , it was $6 \times 30 \mathrm{~s} / 60 \mathrm{~s}$; in the weeks 4 and 5 , it was $7 \times 30 \mathrm{~s} / 60 \mathrm{~s}$; in the weeks 6 to 9 , the recovery period was reduced to $45 \mathrm{~s}(8 \times 30 \mathrm{~s} / 45 \mathrm{~s})$; and in the last two weeks, it was $8 \times 30 \mathrm{~s} / 30 \mathrm{~s}$ [25].

The combined training $(n=29)$ was a combination of resistance and aerobic training, and each session lasted 60 minutes. In the resistance training, the students realized six exercises: leg press, leg extension, leg curl, bench press, lateral pull down, and arm curl. It was composed by three sets of 6-10 repetitions at 60-70\% $1 \mathrm{RM}$ (maximum repetition), and 


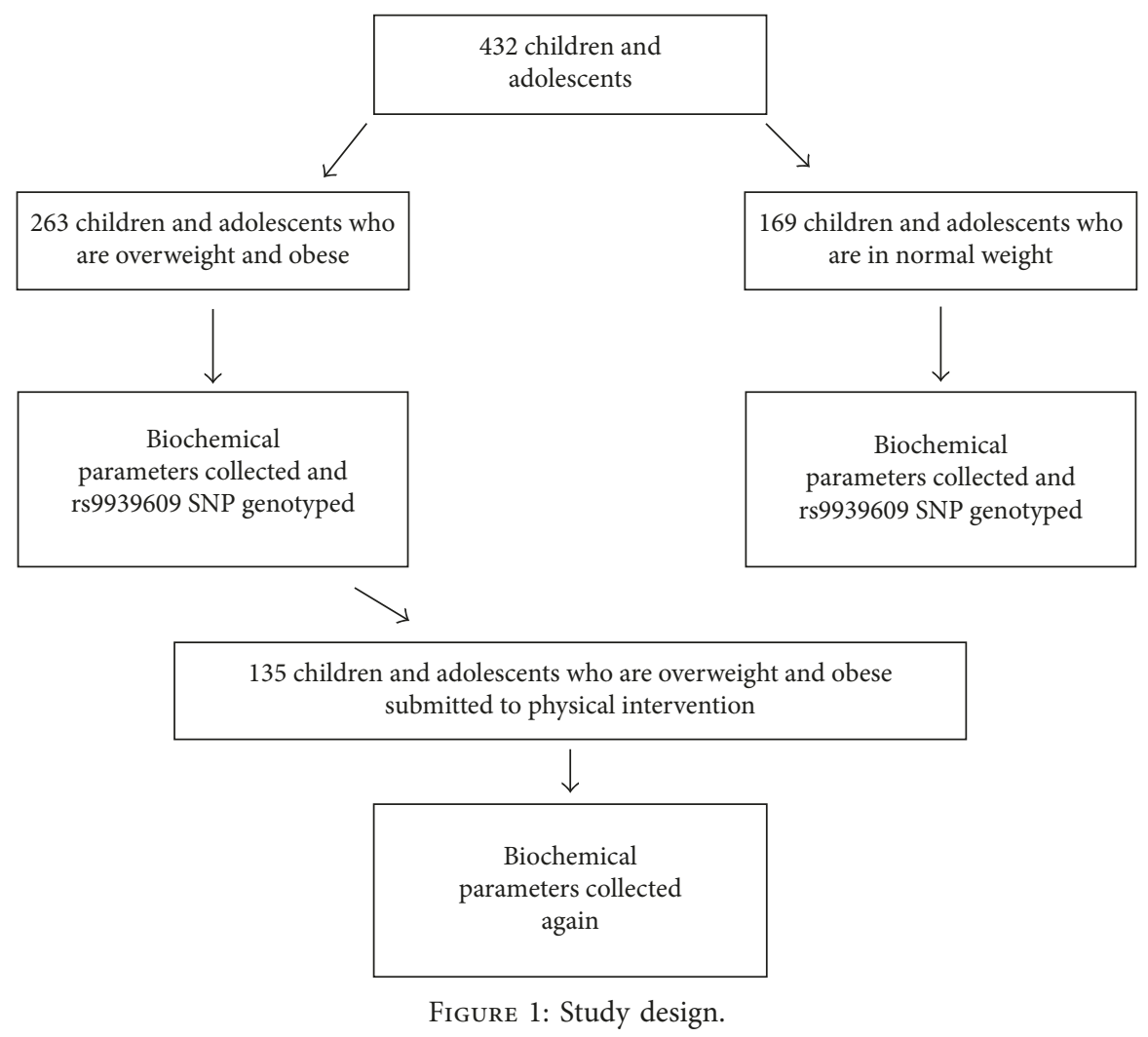

the load was adjusted weekly. In the aerobic training, the students walked/ran in an athletic track for 30 minutes, and the intensity was $50-80 \%$ of $\mathrm{VO}_{2 \text { peak }}$ [26].

The water-walking exercise $(n=26)$ was realized with the support of a float vest attached to the waist, and it is a simulation of walking on land without the contact of the feet with the bottom of the pool. The students realized five minutes of warming up, 45 minutes of walking, and 10 minutes of recovering, totalizing 60 minutes in a session. The exercise intensity was $40 \%$ to $60 \%$ of the RHR and increased in the fifth and ninth weeks [27].

In the statistical analyzes, these groups were analyzed together due to the small number of participants in each one; however, in some analyzes, the type of exercise was added as a correction factor. The analysis of some variables was realized with a smaller number of individuals, since it was not possible to obtain data on all variables from all individuals who completed the program $(n=135)$.

The experimental procedure applied is demonstrated in Figure 1.

2.4. DNA Extraction and Genotyping. DNA were extracted from peripheral blood according to a salting-out technique [28] and then diluted to $20 \mathrm{ng} / \mu \mathrm{l}$. FTO rs9939609 SNP was genotyped with a TaqMan SNP genotyping assay (Applied Biosystems). The reactions were done using the following conditions: $60^{\circ} \mathrm{C}$ for $30 \mathrm{~s}, 95^{\circ} \mathrm{C}$ for $10 \mathrm{~min}, 50$ cycles of $95^{\circ} \mathrm{C}$ for $15 \mathrm{~s}$ and $60^{\circ} \mathrm{C}$ for $1 \mathrm{~min}$, and $60^{\circ} \mathrm{C}$ for $30 \mathrm{~s}$. In each reaction, three previously sequenced control samples were included, representative of each of the possible genotypes.
2.5. Statistical Analysis. The frequencies of genotypes and alleles were obtained by direct counting and compared between the group of overweight/obese and normal weight by chi-square test, which was also used to check the Hardy-Weinberg equilibrium. The continuous variables were tested for normality using the Kolmogorov-Smirnov test with the Lilliefors correction. The recessive, dominant, and lack of dominance models of allelic interaction were tested. The recessive model was adopted for analysis that involved the sample stratification by rs9939609 SNP genotype. For each variable, the means were compared between genotypes by parametric or no parametric tests $(t$ test or Mann-Whitney, resp.). The comparisons between initial and final means (before and after physical exercise) were conducted by the Wilcoxon test or $t$ test for dependent samples.

A two-way mixed ANOVA with repeated measures was used to verify the genotype influence on the response to physical exercise, and the nonparametric variables were normalized by logarithmic transformation. Multiple regression analysis was also applied. Statistical significance adopted for the tests was 0.05 (5\%).

\section{Results}

The risk allele (A) was not associated with obesity in our study (overweight/obese and normal weight group with similar allelic frequency $p=0.71)$. In the overweight and obese group $(n=263), 38.02 \%$ were TT carriers, $48.67 \%$ AT, and $13.31 \%$ AA. The genotype frequencies in the normal weight group $(n=169)$ were $37.28 \%$ (TT), 52.66\% (AT), 
TABLE 1: Initial and final averages of biochemical variables stratified by rs9939609 FTO SNP genotype and effect of exercise ( $p$ value training), genotype ( $p$ value genotype), and training $\times$ genotype interaction $(p$ value $T \times G)$.

\begin{tabular}{|c|c|c|c|c|c|c|c|c|c|c|c|}
\hline \multirow{2}{*}{ Variables } & \multicolumn{4}{|c|}{$\mathrm{TT}+\mathrm{AT}($ mean $\pm \mathrm{SD})$} & \multicolumn{4}{|c|}{$\mathrm{AA}($ mean $\pm \mathrm{SD})$} & \multicolumn{3}{|c|}{$p$ value } \\
\hline & $n$ & Before & After & $\% \Delta$ & $n$ & Before & After & $\% \Delta$ & Training & Genotype & $\mathrm{T} \times \mathrm{G}$ \\
\hline TC (mg/dl) & 118 & $163 \pm 35.81$ & $157 \pm 32.79$ & -3.68 & 17 & $161 \pm 31.75$ & $148 \pm 29.26$ & -8.07 & 0.002 & 0.55 & 0.20 \\
\hline HDL-C (mg/dl) & 117 & $48 \pm 10.9$ & $46 \pm 11.81$ & -4.17 & 17 & $52 \pm 11.95$ & $46 \pm 9.91$ & -11.54 & 0.005 & 0.43 & 0.05 \\
\hline LDL-C (mg/dl) & 118 & $94 \pm 29.5$ & $90 \pm 27.42$ & -4.26 & 17 & $92 \pm 24.27$ & $83 \pm 30.94$ & -9.78 & 0.02 & 0.44 & 0.34 \\
\hline TG (mg/dl) & 117 & $104.44 \pm 53.98$ & $102.71 \pm 52.84$ & -1.66 & 17 & $85.85 \pm 30.35$ & $98.06 \pm 68.54$ & 14.22 & 0.4 & 0.34 & 0.26 \\
\hline Glucose (mg/dl) & 117 & $87 \pm 9.39$ & $86 \pm 8.06$ & -1.15 & 18 & $82 \pm 9.6$ & $80 \pm 5.76$ & -2.44 & 0.07 & 0.003 & 0.77 \\
\hline Insulin (uIU/ml) & 94 & $15.54 \pm 10.93$ & $12.68 \pm 7.81$ & -18.40 & 15 & $20 \pm 14.06$ & $17.58 \pm 9.8$ & -12.10 & 0.02 & 0.07 & 0.84 \\
\hline HOMA-IR & 48 & $1.86 \pm 1.18$ & $1.4 \pm 0.88$ & -24.73 & 8 & $2.86 \pm 1.73$ & $2.53 \pm 1.43$ & -11.54 & 0.06 & 0.007 & 0.74 \\
\hline QUICKI & 43 & $0.34 \pm 0.04$ & $0.36 \pm 0.04$ & 5.88 & 7 & $0.32 \pm 0.03$ & $0.33 \pm 0.03$ & 3.13 & 0.03 & 0.07 & 0.70 \\
\hline
\end{tabular}

TC: total cholesterol; HDL-C: high-density lipoprotein cholesterol; LDL-C: low-density lipoprotein cholesterol; TG: triglycerides; HOMA-IR: homeostatic model assessment for insulin resistance; QUICKI: quantitative insulin sensitivity check index; SD: standard deviation; \% $\Delta$ : percentage variation; $\mathrm{T} \times \mathrm{G}$ : training $\times$ genotype interaction; the test applied was two-way mixed ANOVA.

and $10.06 \%$ (AA). Both groups are in Hardy-Weinberg equilibrium.

A mixed two-way ANOVA test was performed to investigate possible effects of physical intervention (within subject factor: before and after training); genotype (between subject factor: $\mathrm{AA} \times \mathrm{AT}+\mathrm{TT})$; and training $\times$ genotype interaction on the biochemical variables (Table 1). It was possible to observe that the physical intervention and genotype independently influenced the biochemical variables of the children and adolescents who were overweight and obese.

The physical exercise, independently of the FTO rs9939609 genotype, improved the metabolic profile: TC, LDL-C, and insulin levels decreased after the intervention $(p=0.002$, $p=0.02$, and $p=0.02$, resp.), and QUICKI increased $(p=0.03)$, indicating insulin sensitivity improvement of the children who are overweight and obese (Table 1).

The FTO genotype influenced the glucose levels $(p=0.03)$ and HOMA-IR index $(p=0.007)$ (Table 1$)$. Higher HOMA-IR was associated with AA carriers before and after the physical exercise $(p=0.006$ and $p=0.01$, resp.). The same genotype was associated with lower glucose levels only after the intervention $(p=0.002)$ (Supplementary Table 1). According to the ANOVA analysis, the AA carriers trend toward higher levels of insulin $(p=0.07)$ after the physical exercise and lower values of QUICKI ( $p=0.07)$ before and after the physical exercise, compared to TT $+\mathrm{AT}$ carriers (Table 1 and Supplementary Table 1), suggesting that AA genotype could be associated with less favorable insulin profiles. There was no genotype $\times$ training interaction, since the changes in variables after the intervention were not different among genotypes (Table 1).

To investigate the observed trends in ANOVA and identify other factors that contributed to the insulinic profile of children who are overweight and obese, we conducted multiple regression analysis with the initial measures (before), final measures (after), and also with the differences between final and initial values (difference). All the multiple regression analyses were corrected for age, sex, and BMI $Z$-score. Regression analysis with the final and differences values was corrected for the type of exercise practiced (landbased aerobic exercise, high-intensity interval training (HIIT), combined training, or water walking) (Table 2).
The effect of the FTO rs9939609 genotype on the biochemical variables of children and adolescents with normal weight was also evaluated. The comparisons of mean levels of the variables between carriers and noncarriers of AA genotype did not present significant results (Supplementary Table 2), as well as multiple regression analyses (corrected for age, sex, and BMI Z-score) (Table 2).

The regression analysis results confirmed the rs9939609 AA genotype effect in children who are overweight and obese, even after the applied corrections. The initial and final insulin levels were influenced by FTO SNP $(p=0.04$ and $p=0.03$, resp.), as well as the initial HOMA-IR $(p=0.01)$, and final glucose levels $(p=0.003)$. The differences in biochemical variables levels (initial levels - final levels) were not influenced by FTO SNP, which corroborates the absence of the FTO SNP $\times$ training interaction, observed in ANOVA.

\section{Discussion}

Our study was designed to investigate the interaction between FTO rs9939609 SNP and a program of physical exercise on biochemical outcomes of the children and adolescents who were overweight and obese. In this sense, the interaction between the FTO rs9939609 SNP and physical exercise did not affect the biochemical outcomes; however, the FTO rs9939609 SNP was associated with insulin, HOMA-IR, and glucose levels of the children and adolescents who were overweight and obese.

Our study identified an important relationship between AA genotype and less favorable insulin profiles: the mean values of insulin in AA individuals were higher than those recommended by some authors [29]. There are at least two possible ways that would explain this relationship, both involving the FTO overexpression related to rs9939609 A-allele [7].

The most direct relationship between rs9939609 and insulin resistance is suggested by Tschritter and colleagues [30]. They found association between the FTO rs8050136 SNP and cerebrocortical insulin resistance in humans [30], but this polymorphism is in linkage disequilibrium with rs9939609 (rs9939609, $D^{\prime}=0.9998$ [31]); so we cannot rule out a causal effect of the rs9939609 SNP. Tschritter and colleagues observed a reduction of the insulin effect in cortical activity, which 
TABLE 2: Models of multiple regression analysis before and after the physical exercise, with difference values in children and adolescents who are overweight/obese and normal weight.

\begin{tabular}{|c|c|c|c|c|c|c|c|}
\hline \multicolumn{8}{|c|}{ Overweight and obese } \\
\hline \multirow{2}{*}{ Dependent variable } & \multirow{2}{*}{ Independent variables considered } & \multicolumn{2}{|c|}{ Before $(n=263)$} & \multicolumn{2}{|c|}{ After $(n=135)$} & \multicolumn{2}{|c|}{ Difference $(n=135)$} \\
\hline & & $\beta \pm \mathrm{SD}$ & $p$ & $\beta \pm \mathrm{SD}$ & $p$ & $\beta \pm \mathrm{SD}$ & $p$ \\
\hline \multirow{5}{*}{ Glucose (mg/dl) } & Genotype & $0.06 \pm 0.06$ & 0.36 & $0.26 \pm 0.09$ & 0.003 & $-0.03 \pm 0.09$ & 0.76 \\
\hline & Age & $0.07 \pm 0.06$ & 0.28 & $-0.03 \pm 0.09$ & 0.74 & $0.08 \pm 0.09$ & 0.35 \\
\hline & Sex & $-0.06 \pm 0.06$ & 0.36 & $0.16 \pm 0.09$ & 0.07 & $-0.07 \pm 0.09$ & 0.42 \\
\hline & BMI Z-score $\left(\mathrm{kg} / \mathrm{m}^{2}\right)$ & $0.08 \pm 0.06$ & 0.20 & $0.11 \pm 0.09$ & 0.23 & $-0.23 \pm 0.09$ & 0.01 \\
\hline & Type of physical exercise & - & - & $-0.08 \pm 0.09$ & 0.38 & $-0.17 \pm 0.09$ & 0.07 \\
\hline \multirow{5}{*}{ Insulin (uIU/ml) } & Genotype & $-0.13 \pm 0.06$ & 0.04 & $-0.19 \pm 0.09$ & 0.03 & $-0.004 \pm 0.10$ & 0.97 \\
\hline & Age & $0.16 \pm 0.07$ & 0.01 & $0.24 \pm 0.09$ & 0.01 & $-0.03 \pm 0.10$ & 0.79 \\
\hline & Sex & $0.17 \pm 0.06$ & 0.009 & $0.11 \pm 0.09$ & 0.24 & $0.13 \pm 0.10$ & 0.20 \\
\hline & BMI $Z$-score $\left(\mathrm{kg} / \mathrm{m}^{2}\right)$ & $0.35 \pm 0.07$ & $10^{-4}$ & $0.36 \pm 0.09$ & 0.0002 & $-0.0008 \pm 0.10$ & 0.99 \\
\hline & Type of physical exercise & - & - & $0.32 \pm 0.09$ & 0.0005 & $0.05 \pm 0.10$ & 0.60 \\
\hline \multirow{5}{*}{ HOMA-IR } & Genotype & $-0.24 \pm 0.09$ & 0.01 & \multirow{5}{*}{ * } & & \multirow{5}{*}{$*$} & \\
\hline & Age & $0.14 \pm 0.10$ & 0.14 & & & & \\
\hline & Sex & $0.16 \pm 0.09$ & 0.09 & & & & \\
\hline & BMI $Z$-score $\left(\mathrm{kg} / \mathrm{m}^{2}\right)$ & $0.27 \pm 0.10$ & 0.006 & & & & \\
\hline & Type of physical exercise & - & - & & & & \\
\hline \multirow{5}{*}{ QUICKI } & Genotype & $0.12 \pm 0.09$ & 0.20 & & & \multirow{5}{*}{ * } & \\
\hline & Age & $0.05 \pm 0.1$ & 0.59 & & & & \\
\hline & Sex & $-0.27 \pm 0.09$ & 0.004 & $*$ & & & \\
\hline & BMI Z-score $\left(\mathrm{kg} / \mathrm{m}^{2}\right)$ & $-0.38 \pm 0.10$ & 0.0002 & & & & \\
\hline & Type of physical exercise & - & - & & & & \\
\hline \multicolumn{8}{|c|}{ Normal weight $(n=169)$} \\
\hline Dependent variable & Independent variables considered & $\beta \pm \mathrm{SD}$ & $p$ & & & & \\
\hline \multirow{4}{*}{ Glucose $(\mathrm{mg} / \mathrm{dl})$} & Genotype & $-0.07 \pm 0.08$ & 0.37 & & & & \\
\hline & Age & $-0.04 \pm 0.08$ & 0.58 & & & & \\
\hline & Sex & $-0.24 \pm 0.08$ & 0.002 & & & & \\
\hline & BMI $Z$-score $\left(\mathrm{kg} / \mathrm{m}^{2}\right)$ & $0.02 \pm 0.08$ & 0.82 & & & & \\
\hline \multirow{4}{*}{ Insulin (uIU/ml) } & Genotype & $-0.06 \pm 0.07$ & 0.39 & & & & \\
\hline & Age & $-0.03 \pm 0.07$ & 0.73 & & & & \\
\hline & Sex & $0.39 \pm 0.07$ & $10^{-4}$ & & & & \\
\hline & BMI Z-score $\left(\mathrm{kg} / \mathrm{m}^{2}\right)$ & $0.10 \pm 0.07$ & 0.18 & & & & \\
\hline \multirow{4}{*}{ HOMA-IR } & Genotype & $-0.12 \pm 0.09$ & 0.17 & & & & \\
\hline & Age & $0.17 \pm 0.09$ & 0.06 & & & & \\
\hline & Sex & $0.20 \pm 0.09$ & 0.02 & & & & \\
\hline & BMI Z-score $\left(\mathrm{kg} / \mathrm{m}^{2}\right)$ & $0.02 \pm 0.09$ & 0.79 & & & & \\
\hline \multirow{4}{*}{ QUICKI } & Genotype & $0.09 \pm 0.11$ & 0.42 & & & & \\
\hline & Age & $0.19 \pm 0.11$ & 0.09 & & & & \\
\hline & Sex & $-0.14 \pm 0.11$ & 0.21 & & & & \\
\hline & BMI Z-score $\left(\mathrm{kg} / \mathrm{m}^{2}\right)$ & $-0.04 \pm 0.11$ & 0.70 & & & & \\
\hline
\end{tabular}

HOMA-IR: homeostatic model assessment for insulin resistance; QUICKI: quantitative insulin sensitivity check index; $\beta$ : regression coefficient; SD: standard deviation; Genotype: TT + AT and AA (recessive model). ${ }^{*}$ HOMA-IR and QUICKI after physical exercise and differences values have no sufficient variance for the regression analysis; therefore, no results are displayed.

decreases the cerebrocortical response to insulin [30]. Therefore, AA genotype carriers may have reduced insulin effect in the brain, which has led to increased insulin production, resulting in higher insulin values and HOMA index compared to AA genotype noncarriers.

After training, the insulin levels remained higher, and the glucose levels in these individuals were significantly lower compared to AA genotype noncarriers. The practice of physical exercise promotes a reduction in glucose levels, since the muscle contractions generate an increase in glucose uptake through an enhancement in glucose transporter type four (GLUT4) production [32, 33]. However, more studies are necessary to understand the interaction between the rs993960AA genotype, exercise, and glucose outcome.

A less direct relationship between rs9939609 and insulin levels may involve the demethylase function of the FTO [4]. Merkestein and colleagues [34] found that male mice with FTO overexpression have lower adiponectin levels after 20 weeks, which agrees with the reduction in adiponectin levels found in humans who are obese [35]. Adiponectin is a hormone produced mainly in white adipose tissue and has a negative correlation with obesity. All the adiponectin functions are not 
known exactly, but it is probably involved in glucose, TG, and fatty acids decrease. Low levels of this hormone increase the susceptibility to insulin resistance and type 2 diabetes [36]. By binding to its receptors (AdipoR1 and AdipoR2), adiponectin activates the AMP-activated protein kinase (AMPK), which stimulates glucose utilization and fatty-acid combustion. Therefore, the reduction in adiponectin levels would impair the glucose metabolism and insulin sensitivity $[37,38]$. Thus, the FTO rs9939609 SNP can contribute to the adiponectin modulation, and consequently, for the glucose metabolism.

Another possible target of FTO is the ghrelin gene. Karra and colleagues [39] found that cells with FTO overexpression have increased expression of ghrelin mRNA [39]. Ghrelin is a hormone synthesized by the stomach that promotes increased appetite and food intake and decreased insulin sensitivity, among other functions [40]. Therefore, the effects in glucose metabolism observed in the present study can also be explained by ghrelin overexpression.

Additionally, similar to our findings, other studies also observed association of AA genotype with insulin levels and insulin resistance index $[15,41,42]$. Considering that the FTO target genes are not fully known, there is a wide variety of possible genes related to metabolism that may had their expression altered in function of FTO rs9939609 genotype.

We did not find any effect of the rs9939609 AA genotype on biochemical outcomes in response to training physical program. The studies regarding interactions between FTO and physical exercise have controversial results, since some works found interaction [43, 44] and some did not [3,10,45-47]. Those discrepant results could be attributed to the different samples and different ways to analyze the physical activity. Regarding the samples, some studies included children and adolescents $[3,48]$ while others involved adults [43-46]. Kilpeläinen and colleagues [49] showed that the age is an important factor that modulates the FTO and physical exercise interaction, since they observed the interaction between rs9939609 SNP and physical activity only in adults, and not in children and adolescents [49]. Probably other factors also contribute to the heterogeneity in study results, such as gender, ethnicity, and metabolic status.

Moreover, the method of measuring physical activity can also contribute to the heterogeneity, which requires caution in comparisons. Some authors used questionnaires [44, 45, 48], which also differ between them; and other studies analyzed the maximal oxygen uptake $\left(\mathrm{VO}_{2} \mathrm{max}\right)$, resting energy expenditure, and basal metabolic rate $[3,10,41]$. Our study is one of the few that evaluated the rs9939609 effect on biochemical outcomes of the children and adolescents who were overweight and obese submitted to a physical intervention program, which promoted benefits, improving homeostasis regarding CT, LDL-C, insulin, and QUICKI levels.

4.1. Limitations. Our work has some limitations, as the sample size, which did not make possible to separate children and adolescents by gender, age, or type of physical exercise. However, the type of physical exercise was included in the multiple regression analysis, adjusting our results to this variable.
4.2. Conclusions. In conclusion, we found that the rs9939609 AA genotype influenced parameters related to insulin metabolism and did not interact with physical exercise. Studies that seek to identify the effect of the genetic polymorphisms in metabolic markers are important because they can help with prevention alternatives and more individualized treatments, according to the genetic background of each patient. Additionally, these studies may identify different metabolic pathways in which of these genes participate, and, possibly, indicate new insights into pharmaceutical researches.

\section{Conflicts of Interest}

The authors declare they have no conflicts of interest.

\section{Acknowledgments}

This work was supported by Fundação Araucária de Apoio ao Desenvolvimento Científico e Tecnológico do Estado do Paraná, Coordenação de Aperfeiçoamento de Pessoal de Nível Superior (CAPES), and Conselho Nacional de Desenvolvimento Científico e Tecnológico (CNPq). The authors would also like to thank the members of "Núcleo de Qualidadede Vida" (Department of Physical Education, Federal University of Paraná) for the data collection.

\section{Supplementary Materials}

Supplementary Table 1: biochemical variables means compared between carriers and noncarriers of AA genotype before and after the physical exercise in children and adolescents who are overweight and obese. Supplementary Table 2: biochemical variables means compared between carriers and noncarriers of AA genotype in children and adolescents who are normal weight. (Supplementary Materials)

\section{References}

[1] T. M. Frayling, N. J. Timpson, M. N. Weedon et al., "A common variant in the FTO gene is associated with body mass index and predisposes to childhood and adult obesity," Science, vol. 316, no. 5826, pp. 889-893, 2007.

[2] J. E. Cecil, R. Tavendale, P. Watt, M. M. Hetherington, and C. N. A. Palmer, "An obesity-associated FTO gene variant and increased energy intake in children," New England Journal of Medicine, vol. 359, no. 24, pp. 2558-2566, 2008.

[3] K. A. Fawcett and I. Barroso, "The genetics of obesity: FTO leads the way," Trends in Genetics, vol. 26, no. 6, pp. 266-274, 2010.

[4] T. Gerken, C. A. Girard, Y.-C. L. Tung et al., "The obesityassociated FTO gene encodes a 2-oxoglutarate-dependent nucleic acid demethylase," Science, vol. 318, no. 5855, pp. 1469-1472, 2007.

[5] J. K. Hertel, S. Johansson, E. Sonestedt et al., "FTO, type 2 diabetes, and weight gain throughout adult life: a metaanalysis of 41,504 subjects from the scandinavian HUNT, MDC, and MPP studies," Diabetes, vol. 60, no. 5, pp. 16371644, 2011.

[6] R. Liguori, G. Labruna, A. Alfieri et al., "The FTO gene polymorphism (rs9939609) is associated with metabolic syndrome in morbidly obese subjects from southern Italy," Molecular and Cellular Probes, vol. 28, no. 4, pp. 195-199, 2014. 
[7] T. Berulava and B. Horsthemke, "The obesity-associated SNPs in intron 1 of the FTO gene affect primary transcript levels," European Journal of Human Genetics, vol. 18, no. 9, pp. 10541056, 2010.

[8] J. Wardle, C. Llewellyn, S. Sanderson, and R. Plomin, "The FTO gene and measured food intake in children," International Journal of Obesity, vol. 33, no. 1, pp. 42-45, 2009.

[9] J. R. Speakman, K. A. Rance, and A. M. Johnstone, "Polymorphisms of the FTO gene are associated with variation in energy intake, but not energy expenditure," Obesity, vol. 16, no. 8, pp. 1961-1965, 2008.

[10] N. J. Timpson, P. M. Emmett, T. M. Frayling et al., “The fat mass-and obesity-associated locus and dietary intake in children," American Journal of Clinical Nutrition, vol. 88, no. 4, pp. 971-978, 2008.

[11] H.-J. Lee, I. K. Kim, J. H. Kang et al., "Effects of common FTO gene variants associated with BMI on dietary intake and physical activity in Koreans," Clinica Chimica Acta, vol. 411, no. 21-22, pp. 1716-1722, 2010.

[12] J. R. Speakman, “The "Fat Mass and Obesity Related” (FTO) gene: mechanisms of impact on obesity and energy balance," Current Obesity Reports, vol. 4, no. 1, pp. 73-91, 2015.

[13] R. M. Freathy, N. J. Timpson, D. A. Lawlor et al., "Common variation in the FTO gene alters diabetes-related metabolic traits to the extent expected given its effect on BMI," Diabetes, vol. 57, no. 5, pp. 1419-1426, 2008.

[14] D. A. De Luis, R. Aller, O. Izaola, D. Primo, and E. Romero, "Association of the rs9939609 gene variant in FTO with insulin resistance, cardiovascular risk factor and serum adipokine levels in obese patients," Nutrición Hospitalaria, vol. 33, no. 5, pp. 1108-1115, 2016.

[15] C. Muñoz-Yáñez, R. Pérez-Morales, H. Moreno-Macías et al., "Polymorphisms FTO rs9939609, PPARG rs1801282 and ADIPOQ rs4632532 and rs182052 but not lifestyle are associated with obesity related-traits in Mexican children," Genetics and Molecular Biology, vol. 39, no. 4, pp. 547-553, 2016.

[16] J. Prakash, B. Mittal, A. Srivastava, S. Awasthi, and N. Srivastava, "Association of FTO rs9939609 SNP with obesity and obesityassociated phenotypes in a North Indian population," Oman Medical Journal, vol. 31, no. 2, pp. 99-106, 2016.

[17] D. A. Luis, R. Aller, O. Izaola, and D. Pacheco, "Role of rs9939609 FTO gene variant in weight loss, insulin resistance and metabolic parameters after a high monounsaturated vs. a high polyunsaturated fat hypocaloric diets," Nutrición Hospitalaria, vol. 32, no. 1, pp. 175-181, 2015.

[18] D. A. de Luis, R. Aller, O. Izaola et al., "Evaluation of weight loss and adipocytokines levels after two hypocaloric diets with different macronutrient distribution in obese subjects with rs9939609 gene variant," Diabetes/Metabolism Research and Reviews, vol. 28, no. 8, pp. 663-668, 2012.

[19] World Health Organization, Health Topics: Obesity, September 2016, http://www.who.int/topics/obesity/en/.

[20] G. A. do Nascimento, M. Dalcin Teixeira, L. Furtado-Alle et al., "FTO rs9939609 A allele influences anthropometric outcome in response to dietary intervention, but not in response to physical exercise program," European Journal of Nutrition, pp. 1-10, 2017.

[21] W. T. Friedewald, R. I. Levy, and D. S. Fredrickson, "Estimation of the concentration of low-density lipoprotein cholesterol in plasma, without use of the preparative ultracentrifuge," Clinical Chemistry, vol. 18, no. 6, pp. 499-502, 1972.

[22] D. R. Matthews, J. P. Hosker, A. S. Rudenski, B. A. Naylor, D. F. Treacher, and R. C. Turner, "Homeostasis model assessment: IR and beta-cell function from fasting plasma glucose and insulin concentration in man," Diabetologia, vol. 28, no. 7, pp. 412-419, 1985.

[23] A. Katz, S. S. Nambi, K. Mather et al., "Quantitative insulin sensitivity check index: a simple, accurate method for assessing insulin sensitivity in humans," Journal of Clinical Endocrinology \& Metabolism, vol. 85, no. 7, pp. 2402-2410, 2000.

[24] G. E. Milano, N. Leite, T. J. Chaves, G. E. Milano, R. L. R. de Souza, and L. F. Alle, "Atividade da butirilcolinesterase e fatores de risco cardiovascular em adolescentes obesos submetidos a um programa de exercícios físicos," Arquivos Brasileiros de Endocrinologia \& Metabologia, vol. 57, no. 7, pp. 533-537, 2013.

[25] J. Pizzi, L. Furtado-Alle, D. Schiavoni et al., "Reduction in butyrylcholinesterase activity and cardiovascular risk factors in obese adolescents after 12-weeks of high-intensity interval training," Journal of Exercise Physiology Online, vol. 20, no. 3, pp. 110-121, 2017.

[26] W. A. Lopes, N. Leite, L. R. da Silva et al., "Effects of 12 weeks of combined training without caloric restriction on inflammatory markers in overweight girls," Journal of Sports Sciences, vol. 34, no. 20, pp. 1902-1912, 2016.

[27] M. F. A. Lopes et al., "The effects of water walking on the anthropometrics and metabolic aspects in young obese," Revista Brasileira de Cineantropometria \& Desempenho Humano, vol. 17, no. 2, pp. 146-155, 2015.

[28] D. K. Lahiri and J. I. Numberger, "A rapid non-enzymatic method for the preparation of HMW DNA from blood for RFLP studies," Nucleic Acids Research, vol. 19, p. 5444, 1991.

[29] S. Ten and N. Maclaren, "Insulin resistance syndrome in children," Journal of Clinical Endocrinology \& Metabolism, vol. 89, no. 6, pp. 2526-2539, 2004.

[30] O. Tschritter, H. Preissl, Y. Yokoyama, F. Machicao, H.-U. Häring, and A. Fritsche, "Variation in the FTO gene locus is associated with cerebrocortical insulin resistance in humans," Diabetologia, vol. 50, no. 12, pp. 2602-2603, 2007.

[31] W. Chuenta, B. Phonrat, A. Tungtrongchitr et al., "Common variations in the FTO gene and obesity in Thais: a familybased study," Gene, vol. 558, no. 1, pp. 75-81, 2015.

[32] S. Mann, C. Beedie, S. Balducci et al., "Changes in insulin sensitivity in response to different modalities of exercise: a review of the evidence," Diabetes/Metabolism Research and Reviews, vol. 30, no. 4, pp. 257-268, 2014.

[33] A. García-Hermoso, J. M. Saavedra, Y. Escalante, M. SanchezLopez, and V. Martinez-Vizcaino, "Endocrinology and adolescence: aerobic exercise reduces insulin resistance markers in obese youth: a meta-analysis of randomized controlled trials," European Journal of Endocrinology, vol. 171, no. 4, pp. R163-R171, 2014.

[34] M. Merkestein, J. S. McTaggart, S. Lee et al., "Changes in gene expression associated with FTO overexpression in mice," PLoS One, vol. 9, no. 5, article e97162, 2014.

[35] Y. Arita, S. Kihara, N. Ouchi et al., "Paradoxical decrease of an adipose-specific protein, adiponectin, in obesity," Biochemical and Biophysical Research Communications, vol. 257, no. 1, pp. 79-83, 1999.

[36] A. Shehzad, W. Iqbal, O. Shehzad, and Y. S. Lee, "Adiponectin: regulation of its production and its role in human diseases," Hormones, vol. 11, no. 1, pp. 8-20, 2012.

[37] T. Kadowaki, T. Yamauchi, N. Kubota, K. Hara, K. Ueki, and K. Tobe, "Adiponectin and adiponectin receptors in insulin resistance, diabetes, and the metabolic syndrome," Journal of Clinical Investigation, vol. 116, no. 7, pp. 1784-1792, 2006.

[38] N. Kubota, Y. Terauchi, T. Yamauchi et al., "Disruption of adiponectin causes insulin resistance and neointimal 
formation," Journal of Biological Chemistry, vol. 227, no. 29, pp. 25863-25867, 2002.

[39] E. Karra, O. G. O’Daly, A. I. Choudhury et al., “A link between FTO, ghrelin, and impaired brain food-cue responsivity excellence cluster on cellular stress responses in agingassociated diseases," Journal of Clinical Investigation, vol. 123, no. 8, pp. 3539-3551, 2013.

[40] L. Mihalache, A. Gherasim, O. Niță et al., "Effects of ghrelin in energy balance and body weight homeostasis," Hormones, vol. 15, no. 2, pp. 186-196, 2016.

[41] S. I. I. Kring, C. Holst, E. Zimmermann et al., "FTO gene associated fatness in relation to body fat distribution and metabolic traits throughout a broad range of fatness," PLoS One, vol. 3, no. 8, article e2958, 2008.

[42] S. Tan, A. Scherag, O. E. Janssen et al., "Large effects on body mass index and insulin resistance of fat mass and obesity associated gene (FTO) variants in patients with polycystic ovary syndrome (PCOS)," BMC Medical Genetics, vol. 11, no. 1, p. 12, 2010.

[43] M. Muc, C. Padez, and L. Manco, "Influence of physical activity on the association between the FTO variant rs9939609 and adiposity in young adults," American Journal of Human Biology, vol. 27, no. 5, pp. 734-738, 2015.

[44] J. Petkeviciene, A. Smalinskiene, J. Klumbiene, V. Petkevicius, V. Kriaucioniene, and V. Lesauskaite, "Physical activity, but not dietary intake, attenuates the effect of the FTO rs9939609 polymorphism on obesity and metabolic syndrome in Lithuanian adult population," Public Health, vol. 135, pp. 23-29, 2016.

[45] A. Jonsson, F. Renström, V. Lyssenko et al., "Assessing the effect of interaction between an FTO variant (rs9939609) and physical activity on obesity in 15,925 Swedish and 2,511 Finnish adults," Diabetologia, vol. 52, no. 7, pp. 1334-1338, 2009.

[46] T. Berentzen, S. I. I. Kring, C. Holst et al., "Lack of association of fatness-related FTO gene variants with energy expenditure or physical activity," Journal of Clinical Endocrinology \& Metabolism, vol. 93, no. 7, pp. 2904-2908, 2008.

[47] A. Leońska-duniec, Z. Jastrzębski, A. Zarębska, A. Maciejewska, K. Ficek, and P. Cięszczyk, "Assessing effect of interaction between the FTO A/T polymorphism (rs9939609) and physical activity on obesity-related traits," Journal of Sport and Health Science, vol. 352, 2016.

[48] E. T. Liem, J. M. Vonk, P. J. Sauer et al., "Influence of common variants near INSIG2, in FTO, and near MC4R genes on overweight and the metabolic profile in adolescence: The TRAILS (TRacking Adolescents' Individual Lives Survey) Study," American Journal of Clinical Nutrition, vol. 91, no. 2, pp. 321-328, 2010.

[49] T. O. Kilpeläinen, L. Qi, S. Brage et al., "Physical activity attenuates the influence of FTO variants on obesity risk: a meta-analysis of 218,166 adults and 19,268 children," PLoS Medicine, vol. 8, no. 11, p. e1001116, 2011. 


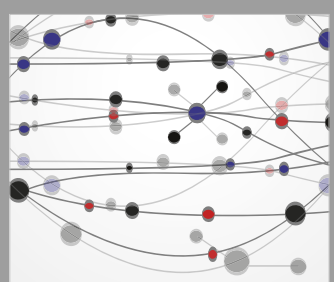

The Scientific World Journal
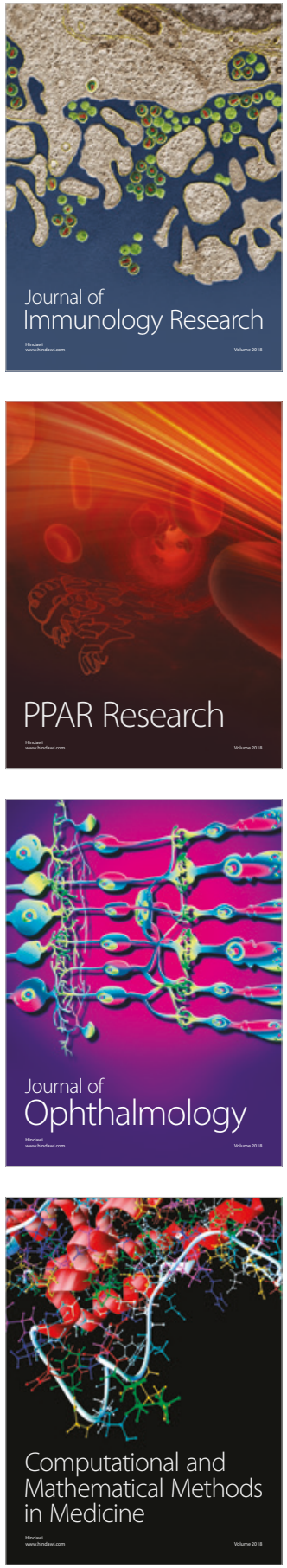

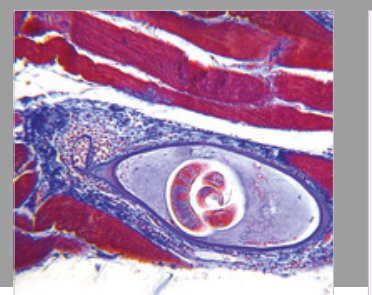

Gastroenterology Research and Practice

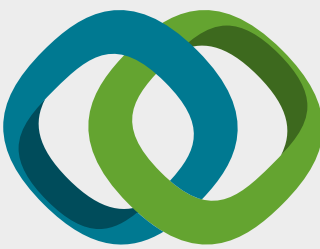

\section{Hindawi}

Submit your manuscripts at

www.hindawi.com
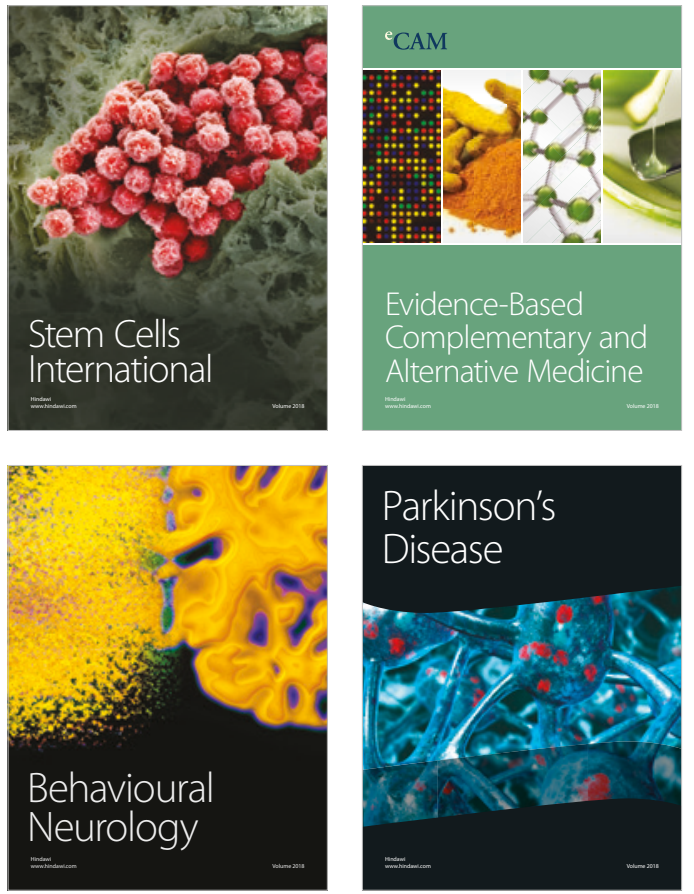

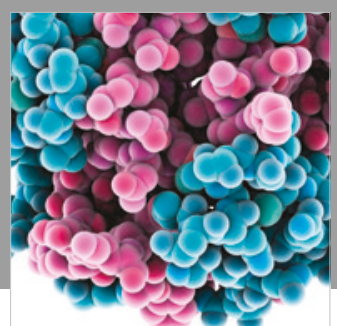

ournal of

Diabetes Research

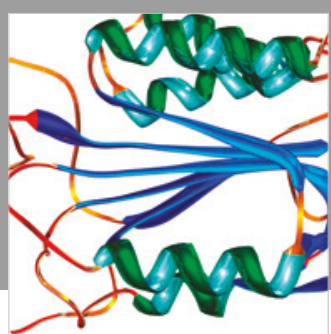

Disease Markers
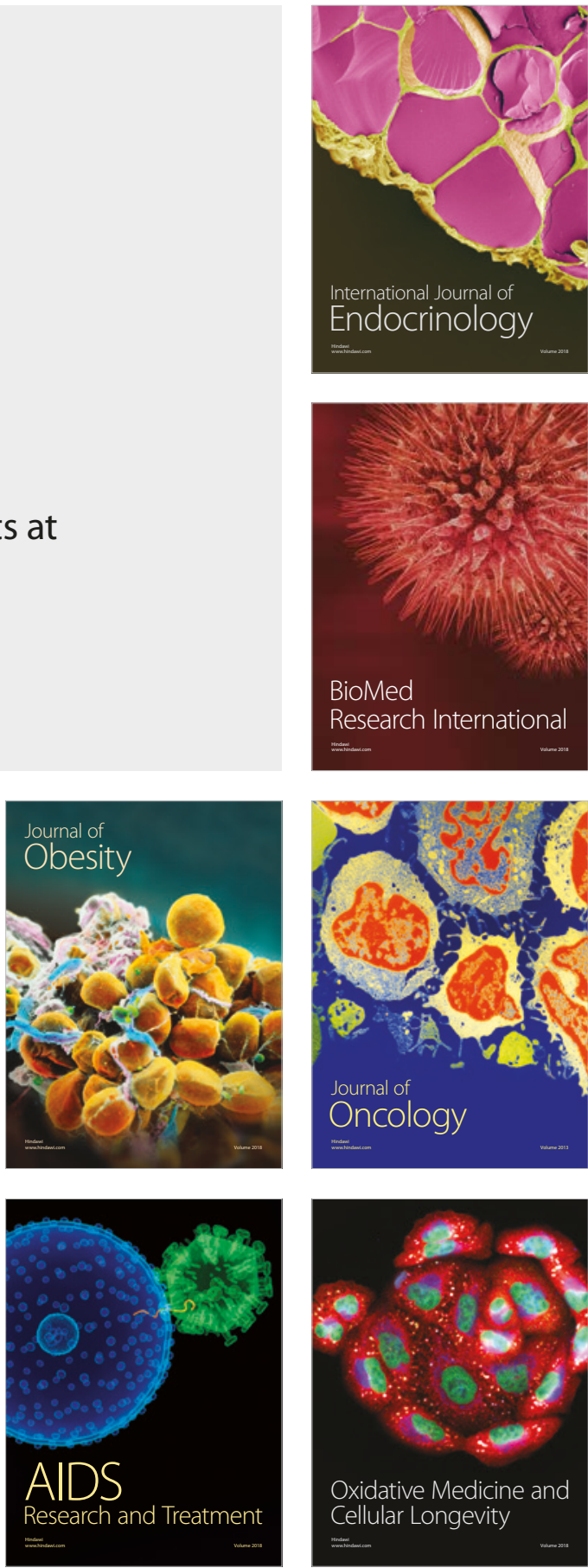